\title{
Queering Queer Theory: Debating Male-Male Prostitution in the Chinese Media
}

(C) Elaine Jeffreys 2006

University of Technology, Sydney

\begin{abstract}
This paper examines media publicity surrounding the case of Li Ning-a 34-year-old native of Nanjing City, Jiangsu Province, who made legal history in the People’s Republic of China (PRC) on 17 October 2004 when he was sentenced to eight years jail and fined 60,000 yuan for organizing male-male prostitution services in a recreational business enterprise. Reputedly the first conviction of its kind, the case proved to be controversial for three main reasons. First, it prompted legal debate over the nature of China's recent shift to a 'rule of law' and associated conceptions of due legal process, and individual and sexual rights. Second, it intimated that homosocial prostitution —-male-male prostitution in which neither participant may self-identify as homosexual—is an integral but frequently neglected component of China's burgeoning, albeit banned, sex industry. Finally, it raised questions regarding the perceived appropriate parameters of same-sex sexual conduct in a country facing rapidly increasing rates of HIV/AIDS infection. An examination of media coverage of these concerns suggests that accusations of official homophobia in the PRC are overstated. They elide the specificity of debates on homosexuality in present-day China due to their overarching concern with Western understandings of sexuality as constitutive of selfhood and (right-ful) socio-political identity.
\end{abstract}




\section{Queering Queer Theory: Debating Male-Male Prostitution in the Chinese Media}

In an article entitled 'Talking sex', Dennis Altman (2000: 176) contends that the problem with queer theory is that it has failed to imagine itself outside of the 'Iron Triangle of London, Paris and New York’. The 'development of genuinely new regimes of sexuality and gender', he continues, 'seems more likely to emerge from Rio, Manila and Soweto than the hyperacademized hothouses of western theory’ (ibid.). Putting Altman’s utopian gesture to some better and future sexuality aside, the point to note is that scholars have queried the queer tendency to mobilize an idealized image of 'the West' as a yardstick by which to measure the perceived progress or failings of gay and lesbian cultures around the globe (Chu 2003: 194-99). As Grewal and Kaplan (2001: 669) explain, metropolitan studies of sexuality in non-western contexts have tended to reproduce the tradition/modernity divide by reifying Euramerica as the site of the modern, and hence of progressive social movements, while other parts of the world are presumed to be traditional and oppressive, especially with regards to sex and sexuality. Such studies have thus failed to consider how different nation-states, forms of governmentality, economic formations, and consumer cultures, produce and uphold diverse sexual subjectivities and communities in an increasingly globalized world (ibid: 669-70).

The tendency of metropolitan studies of sexuality to reify Euramerica as a unified site of 'modern freedoms’ owes much to the apparent and perceived lack of sexual rights in many developing countries. The NGOization of social movements-in 'the form of the emergence of global feminism as a policy and activist area'; struggles by gay, lesbian and other activists; and the imperatives of HIV/AIDS prevention programs - has seen the extension of Western liberal 
conceptions of human rights to the rest of the world (ibid: 665). Although some postcolonial and queer theorists have criticized the neo-colonialist implications of this particular form of globalization, for valorizing Western-style sexual liberation as the 'the only possible progressive trajectory', and for constructing universal and potentially oppressive Feminist and Gay subjects (Altman 2000: 174), such criticisms tend ultimately to be rejected on the grounds that they sound too close to arguments against a universal respect for human rights and therefore offer support to traditional and repressive regimes (ibid.).

The People's Republic of China (PRC) is an oft-cited example of a country that is allegedly traditional and repressive vis-à-vis the governmental regulation of sexuality, especially homosexuality. Fran Martin (2000: 81), for example, begins her discussion of the emergence of a queer counterpublic in Taipei by stating that the 'official treatment of "homosexuality" (tongxinglian) in 1990s Taiwan presents a marked contrast to its representation in other states within the region', such as the PRC and Singapore. In contrast to Taiwan's 'official' if apparently still belated 'embrace of liberal sexual politics’, Martin suggests that mainland China is characterized by 'official homophobia' and a failure to recognize what are construed as the natural rights of sexual minorities (ibid: 81, 84). Wan Yanhai (1997), a Chinese activist for gay rights, similarly maintains that the PRC is a Party-police-state that refuses to recognize the rights of gays and other sexual minorities, including their assumed right to consume and provide commercial sexual services.

This paper questions these claims and contributes to the task of thinking about issues of sex and sexuality transnationally with reference to the case of Li Ning-a 34-year-old native of Nanjing 
City, Jiangsu Province, who made legal history in the PRC on 17 October 2004 when he was sentenced to eight years jail and fined 60,000 yuan for organizing male-male prostitution services in a recreational business enterprise (Fu 2004; Xiao and Qin 2004). Reputedly the first conviction of its kind, the case attracted national and international media coverage and was nominated as one of ‘China’s 10 biggest legal cases in 2004' (Zhang Ning 2005). ${ }^{1}$ The case attracted widespread controversy for three reasons. First, it prompted legal debate over the nature of China's recent shift to a 'rule of law' and associated conceptions of due legal process, and individual and sexual rights (Guo Xiaofei 2004). Second, it intimated that homosocial prostitution—male-male prostitution in which neither participant may self-identify as homosexual—is an integral but frequently neglected component of China’s burgeoning, albeit banned, sex industry (Xiao and Qin 2004). Finally, it raised questions regarding the perceived appropriate parameters of same-sex sexual conduct in a country facing rapidly increasing rates of HIV/AIDS infection (Guo Xiaofei 2004; Lü Fuming 2004). An examination of media coverage of these concerns suggests that accusations of official homophobia in the PRC are overstated. They elide the specificity of debates on homosexuality in present-day China due to their overarching concern with Western understandings of sexuality as constitutive of selfhood and (right-ful) socio-political identity.

\section{Contextualizing media coverage of China's first same-sex prostitution case}

The act of organizing, inducing, introducing, facilitating, or forcing, another person to engage in prostitution is a criminal offence in China, punishable by up to five or up to ten years imprisonment with the possible addition of a fine, according to the PRC's first criminal code, 
promulgated on 1 January 1980, and the revised 1997 Criminal Law of the PRC (see Articles 358-9). First-party participation in the prostitution transaction is not criminalized; but engagement in the prostitution transaction is banned as constituting a social harm and a violation of the rights of 'woman-as-person', punishable by a maximum of 15 days detention for investigation and the possible addition of a fine; and, in more serious cases, by between six months and two years detention for reform through education and/or labour with the possible addition of a fine, according to the Chinese system of administrative sanctions (Quanguo renda changweihui, xingfashi bianzhu, fazhi gongzuo weiyuanhui 1991). The Chinese system of administrative sanctions came into being during the Maoist period (1949-76), when the legal system fell into disrepute as a tool of class-based oppression. It is now used, and not without criticism, alongside the formal legal system to police the activities of those who are deemed to have committed social offences, but whose criminal liability is not deemed sufficient to bring them before the courts (Starr 2001: 204-19). This means that the vast majority of prostitutionrelated offences, i.e., the processes of investigating, determining guilt, and suitably penalizing, the activities of sellers and buyers of sex, are handled by the Chinese police, with only serious cases, such as those relating to the organization of prostitution, forced prostitution, and trafficking in women and children, being handled through the courts and criminal justice system (Jeffreys 2004: 138-49). Hence, the emerging body of Chinese prostitution law can be technically described as abolitionist rather than prohibitionist, in that it aims to criminalize thirdparty involvement in the running of prostitution businesses, as opposed to first-party participation in the prostitution transaction per se (ibid.). 
The PRC's legally articulated commitment to abolishing the prostitution industry owes much to the history of the Chinese revolution. Along with its assumption of political power in 1949, the Chinese Communist Party (CCP) embarked upon a series of campaigns that purportedly eradicated prostitution from the mainland by the late 1950s (ibid.: 96). The extraordinary nature of this feat, irrespective of its actual validity, meant that the eradication of prostitution was (and still is) vaunted as one of the major accomplishments of the new regime. Indeed, a Chinese government white paper describes it as effecting an 'earth-shaking historic change in the social status and condition of women' ('Historic liberation of Chinese women’ 2000). Following Engels ([1884] 1972), the early CCP viewed the institution of prostitution as an expression of the exploited and denigrated position of women under capitalism-patriarchy, and therefore as incompatible with the desired goals of building socialism and establishing more equitable sociosexual relations. Since the early 1980s, however, along with the shift from a planned to a market economy, governmental authorities in China have acknowledged that the phenomenon of prostitution has not only reappeared on the mainland, it also constitutes a widespread and growing problem. In fact, it is now considered that the introduction of new laws and regulatory measures has failed to curb the prostitution business, especially its proliferation in diverse forms throughout China's new and burgeoning hospitality and service industry (Jeffreys 2004: 96-102).

The Li Ning case, or the 'Nanjing same-sex prostitution case' as it has become known, thus achieved notoriety as the first widely publicized conviction for organized male-male prostitution in the history of the PRC. ${ }^{2}$ According to Chinese media reports, the details of this case are as follows. On 17 August 2003, the Qinhuai District Police in Nanjing City detained Li Ning for investigation for organizing prostitution, in the form of recruiting young men to provide 
'companionship' and commercial sexual services to male clients of the 'Zhengqi Bar' for an estimated profit of 124,700 yuan (Guo Xiaosong 2004; Liu Zhi (n.d.); Zong and Yang 2004). The Qinhuai police asserted that Li and his accomplices had advertised in local newspapers, and on street posters, for young men (approximately 18-19 years of age) to work in 'marketing' or ‘public relations’ during May 2003, and subsequently had opened a bar with facilities for smallscale musical and other entertainment in July 2003 (Guo Xiaosong 2004). It was alleged that most of the respondents to this advertising campaign self-identified as heterosexual and did not realize the actual nature of the work they were expected to perform. But, having paid a 300 yuan non-refundable deposit for the job and being expected to pay Li Ning a 200 yuan monthly 'management fee', some had agreed either voluntarily or flowing from financial coercion to accompany male clients of the venue to eat, drink and sing, in exchange for financial recompense, and others had consented to provide commercial sexual services ('Couple arrested in China for running gay prostitution bar’ 2003; Fan and Guo 2004; Guo Xiaosong 2004; Liu Zhi (n.d.)). The Qinhuai police further asserted that Li Ning had opened a series of such bars in consecutive fashion since 1999; that is, Li had a documented history of conducting such business, and therefore should be handled according to the full weight of the criminal law. Moreover, in the case of the Zhengqi Bar, they could prove that he had organized young men to provide commercial sexual services to male patrons of the venue and that he had commanded a ‘commission’ for doing so on at least seven occasions (Guo Xiaosong 2004).

The case opened for a closed hearing on 6 February 2004 reputedly to ensure that the verdict would not be prejudiced by public opinion (Xiao and Qin 2004). Journalists and members of the public were precluded from attending due to the controversial nature of the case as relating to 
male-male prostitution; and, due to the fact that the Nanjing procurator originally had released Li Ning from police custody on 25 September 2003. Li was released on the basis that he had already spent 30 days in police custody and there was no legal case to be prosecuted, since the PRC has no written laws or regulations explicitly criminalizing the organization of same-sex as opposed to opposite-sex prostitution (Fu 2004; Xiao and Qin 2004). Unsatisfied with this decision, police officials in Nanjing City applied to the Jiangsu Province Political and Legal Committee for a review of the case between late September and early October 2003 (Xiao and Qin 2004). Upon debating the case and concluding that the prostitution industry is banned in the PRC as constituting a social harm, that committee applied to the Chinese Supreme Court for further advice on how to proceed, a request which was presented, in turn, to China’s top legislative body, the Standing Committee of the National People's Congress (NPC). In late October, the Legal Affairs Committee of the NPC made an oral reply to the effect that Li Ning should be prosecuted based on Article 358 of the Chinese criminal code, which suggests that the organization and facilitation of all commercial sex acts, irrespective of whether those acts occur between members of the opposite or same sex, is unlawful (Fu 2004). Following this response, the Nanjing procurator filed a suit with the Qinhuai District People’s Court on 2 January 2004 charging Li Ning with organizing prostitution. The case opened on 6 February and concluded with his sentencing on 17 February for seven counts of organizing prostitution (ibid.).

Li Ning's lawyer, Chen Yi, requested that the charges against the defendant be dismissed on four grounds. First, Chen argued that there were no relevant laws and regulations to convict Li Ning, since the Chinese criminal code contains no explicit reference to the issue of same-sex prostitution (Guo Xiaosong 2004). The PRC’s ban on prostitution, he continued, was designed 
historically to oppose the exploitation of women by men and that understanding constitutes the basis of social condemnation of the prostitution industry in China today. Contemporary Chineselanguage dictionaries, for example, define prostitution as characterized by the commodified exchange of transient sexual relations for money, with the providers of such services being gendered as female and those who demand such services as male (Wei 2004). In addition, Article 3 of the Criminal Law of the PRC (1997), in Chapter 1, 'Tasks, Scope of Application and Basic Principles', states that: [a]ny act deemed by explicit stipulations of law as a crime is to be convicted and given punishment by law and any act that no explicit stipulations of law deems a crime is not be to be convicted or given punishment'. Chen therefore concluded that the charges against Li Ning should be dismissed since it was impossible to say that he had committed a crime legally (Liu Yaping 2004)

Second, Chen Yi drew on the popular (liberal) argument that the prostitution transaction is a private transaction that occurs between consenting adults and therefore should not be subjected to criminal sanctions because it constitutes a mala prohibita or victimless crime (e.g. Li Yinhe 2005; Shi (n.d)). Arguing that the PRC’s historical and Marxist-based objection to prostitution as an example of the feudal-patriarchal-capitalist-exploitation of women is outdated if wellintentioned, Chen maintained that no individual had been harmed by Li’s business activities, hence criminal charges were unnecessary (Zong and Yang 2004). Adding to this point, Chen maintained that Li Ning may have facilitated actions that contravened social morality, but he had not committed a criminal offence. In consequence, Chen concluded that Li Ning should be tried according to the more lenient provisions outlined in the Chinese system of administrative sanctions, rather than on the basis of the criminal code (ibid.). 
Third, Chen Yi contended that Li Ning should not be prosecuted for organizing prostitution per se, since he could only be held responsible for the management of activities that occurred within the Zhengqi Bar, not those that occurred outside of the premises (Xiao and Qin 2004). In modern Chinese, this distinction is referred to as the difference between activities known as zuotai and those known as chutai. Zuotai (literally, at the 'business' counter) refers to the fact that the services of female or male service personnel may be available within a given entertainment or recreational business enterprise for the purpose of providing 'companionship' to the venue's clientele. Service personnel may provide companionship in the form of eating, drinking, and singing and dancing, etc., with the patrons of a given venue in exchange for financial recompense in the form of 'tips' and/or a commission on the monies forwarded for the consumption of food and beverages, and the use of a semi-privatized space to participate in karaoke and so forth. Technically speaking, the exchange of money for companionship in recreational venues is banned according to the PRC’s 1999 'Regulations concerning the management of public places of entertainment' (Zhonghua renmin gongheguo guowuyuan 1999). However, such services are widely available in practice within the confines of recreational venues. In contrast, chutai (literally, away from the 'business' counter) refers to the fact that service personnel may make individual arrangements to engage in other activities, including commercial sexual activities, outside of the recreational venue where they are theoretically employed. ${ }^{3}$ Chen's defence of Li Ning thus turned on the suggestion that 'employers' cannot be held responsible for what occurs outside of their business premises and responsible supervision (Xiao and Qing 2004). 
Finally, Chen Yi concluded that there was insufficient evidence to tie Li Ning to the seven counts of organizing prostitution that had been laid against him (Zong and Yang 2004). According to Chen, the charges were based on oral testimonies and insubstantial evidence. The Qinghuai police had built their case around the testimonies provided by several young men who had 'worked' in the Zhengqi Bar and who were thus keen to displace legal attention away from their own activities and towards Li Ning. Concomitantly, Chen maintained that the charges and associated profits that were laid against Li could neither be proved to be the direct product of his actions nor his sole responsibility. Given that Li's alleged 'accomplices’ had absconded, he claimed that Li Ning was being held responsible in an exclusive fashion for the criminal actions of other people. Chen therefore concluded that there was insufficient evidence to tie Li Ning to the seven counts of organizing prostitution that had been laid against him (ibid.).

In sentencing Li Ning to eight years jail and a fine of 60,000 yuan for organizing male-male prostitution services in a recreational business enterprise, the court clearly disagreed with Chen’s defence. This sentence was meted on the grounds that the Chinese criminal code may not contain any explicit regulations regarding the handling of same-sex prostitution, but it proscribes the act of organizing, inducing, introducing, facilitating, or forcing, another person to engage in prostitution (Xiao and Qin 2004). In other words, Li Ning's conviction turned on the contention that the body of Chinese prostitution law is non-gender specific and hence covers the facilitation of prostitution practices between members of the opposite or same sex, irrespective of historical and legal precedent. The court further determined that the case should not be handled in a lenient manner, i.e., according to the Chinese system of administrative sanctions as opposed to the penal code, because Li Ning's refusal to admit his guilt, in keeping with the fault-based orientation of 
Chinese law, indicated that he felt no remorse and refused to admit any responsibility for the consequences of his actions (ibid.).

Despite the closed nature of Li Ning's trial, the handing down of this sentence generated widespread public debate. Lawyers and legal scholars, in particular, entered into a mediainduced debate about Li's conviction, one that raised questions about the PRC's proclaimed shift to a 'rule of law' and associated conceptions of due legal process and individual and sexual rights (Guo Xiaofei 2004). Accordingly, the next section of this paper examines the broader legal debate that was generated by Li’s conviction.

\section{Debating the legal implications of China's first same-sex prostitution case}

Legal commentators who dispute Li Ning's conviction insist that it was both unlawful and unconstitutional to try him; hence, the court proceedings demonstrate the PRC’s lack of regard vis-à-vis the protection and promotion of individual rights, particularly those of participants in same-sex sexual behaviours (Yao Zixu (n.d.)). The basic contention here, in keeping with Chen Yi's defence, is that the Chinese criminal code may adopt gender-neutral language in stating that the organization and facilitation of prostitution is a crime, but it makes no explicit reference to the subject of same-sex prostitution (Articles 358-9, Criminal Law of the PRC, 1997). This consideration, taken in conjunction with the elimination of the use of precedent as stipulated in Article 3 of the penal code, indicates that the act of providing same-sex commercial sexual services cannot be construed as a criminal offence, because there is no explicit reference to this offence in Chinese law (Wei 2004; Yao Zixu (n.d.)). Critics further aver that, if the use of 
precedent is considered to be acceptable legal practice, then, the case should have been dismissed outright. This is because, in November 1998, a case relating to the organization of homosocial prostitution in a teahouse in Chengdu City, Sichuan Province, was dismissed on the grounds that there was no legal basis to deal with the phenomenon of same-sex prostitution in Chinese law (Liu Yaotang 2004; see also 'China: law faces sex problems—Sichuan teahouse case’ 1999).

Critics of Li Ning's conviction also maintain that the case proceedings underscore the PRC's failure to adopt a 'rule of law' by demonstrating that individuals are denied the right to a fair trial. Accusations of unfair proceedings relate to the practice of law-enforcement agencies appealing to higher authorities for instructions on individual cases, thereby allegedly compromising both the defendant's right of appeal and the impartiality and independence of the different levels that make up China’s legal system (Wei 2004; Yang Tao (n.d.)). In Li Ning’s case, critics contend that his conviction resulted from the NPC's oral response to requests for advice on how to proceed with the case from lower-level law-enforcement agencies. As they argue, the oral nature of that response, combined with the fact that the NPC is a legislative and not a judiciary body, suggests that Li Ning's conviction was based on the non-verifiable and subjective opinions of an unspecified body of the NPC rather than on the basis of the implicitly impartial and objective letter of the law (ibid.). In short, critics maintain that the NPC's reply not only effectively rendered Li Ning's defence null and void, but also compromised the desired independence of the lower-levels of China's legal system, by giving 'higher authorities' the power to determine how a specific case, as opposed to generalized legal norms, should be handled (Wei 2004). 
Critics of Li Ning's conviction further claim that the severity of his sentence demonstrates that the Chinese legal system, akin to the general public, is homophobic (Guo Xiaofei 2004). The basic argument here is that eight years imprisonment is a harsh punishment for the act of facilitating and organizing prostitution, particularly when those acts are viewed as consensual. Hence, Li was sentenced on the basis of social distaste for homosexual behaviour, that is, for failing to conform to heterosexual norms. According to critics of Li Ning's conviction, the Chinese public and Chinese law enforcement agencies are uninformed about the subject of homosexuality, and not only look upon same-sex sexual acts with repugnance, but also blame participants in same-sex sexual practices for the spread of HIVS/AIDS in China today (ibid.). The severity of Li's sentence is thus taken as evidence of the perceived failure of the Chinese Government to protect and promote both individual rights and the rights of sexual minorities.

Conversely, other legal commentators proved keen not only to establish the legality of Li Ning's conviction, but also to demonstrate that arguments alleging that he was sentenced for being 'a homosexual' were untenable (Yao Zixu (n.d.)). According to upholders of Li's conviction, the court neither ruled against the right of individuals to engage in same-sex sexual practices nor against their right to define themselves as homosexuals: it merely ruled against third-party profiteering from the organization of the prostitution of others (ibid.). Contrary to accusations of official homophobia, supporters of Li Ning’s conviction maintain that there are no legal prohibitions against same-sex sexual behaviours in the Chinese criminal code. Likewise, there are no legal prohibitions against same-sex sexual behaviours in the Chinese system of administrative and Party disciplinary sanctions. The revised Criminal Law of 1997 eliminated previous references to the crime of sodomy (jijianzui) and to the problematic category of 
'hooliganism' (liumangzui), which was formerly often used to police the activities of participants in same-sex sexual behaviours. Hence, the only laws against same-sex sexual behaviours in China today are designed to prohibit sex with minors, and therefore to protect the rights of children; to prohibit non-consensual sex, and therefore to penalize rape; and to ban practices that are likely to cause public offence, such as committing sex acts in public and engaging in group sex in places patronized by members of the public (Yao Zixu (n.d.)). As supporters of Li Ning's conviction continue, the existence of these laws, and laws against the organization of same-sex prostitution, are supported by members of China's homosexual community, as evidenced by the fact that commentators on the Aibai gay website agreed with Li's sentencing, even as they called for greater tolerance of same-sex love (Guo Xiaosong 2004).

Supporters of Li Ning's conviction further emphasize that Chinese law may be opposed to the organization of prostitution, but it is certainly not 'anti-gay', by arguing that the conviction flowed from adherence to correct legal procedure. As they argue, the use of precedent in $\mathrm{Li}$ Ning's case was entirely appropriate. The Chinese criminal code may not make any explicit reference to the subject of same-sex prostitution. It may also be the case that common law and common-sense are gendered, in that a prostitute is assumed to be a woman who exchanges sex with men for money or financial recompense (Wei 2004). However, the spirit of the law clearly opposes the organization of prostitution in any form since chapter six of the penal code bans the organization and facilitation of 'others' (taren) to engage in prostitution as crime that obstructs the correct administration of public order, and hence as something that constitutes a social harm. Furthermore, the clearest existing instruction on same-sex prostitution in the Chinese legal system to date, namely, the 2001 'Reply from the Ministry of Public Security on how to define 
and handle the exchange of same-sex sexual conduct for money or property', explicitly states that those who offer and/or buy transient sexual relations, whether between members of the opposite and/or same sex, for money or property as the medium of exchange, including the provision of oral sex, hand-jobs, anal sex, and so forth, should be treated as engaging in prostitution and handled according to the law ('Gonganbu guanyu dui tongxing zhijian yi qiancai wei meijie de xingxingwei dingxing chuli wenti de pifu’ 2001). ${ }^{4}$ In short, this instruction suggests that the organization of same-sex prostitution should be handled in precisely the same manner as heterosexual prostitution. Consequently, upholders of Li Ning's conviction maintain that he was sentenced in keeping with correct legal procedure, since the case does not concern a new type of crime that requires specific legislation (Guo Xiaofei 2004; Yao Zixu (n.d.). Moreover, the fact that the case was referred to the NPC may highlight the failure of lower-level courts to understand and apply the law, but it cannot be used to exculpate Li Ning from criminal responsibility.

Although legal commentators continue to debate whether the organization of homosocial prostitution can be considered a crime or not, the NPC's reply on the Li Ning case effectively gave the Chinese police the 'green light' with regard to law enforcement. Media coverage of Li Ning's conviction was soon followed by discussions of similar cases in the Chinese media. On 18 May 2004, in what was described as the first case of organized male-male prostitution in China’s northeastern province of Jilin, the Nanguan District People’s Court in Changchun City sentenced Ren Guohui, Song Shuang, and Na Yan, respectively, to 13 years imprisonment and a fine of 20,000 yuan, six and half years imprisonment and a fine of 10,000 yuan, and to six years imprisonment and a fine of 10,000 yuan, for recruiting young men to provide commercial male- 
male sexual services in recreational venues, such as hotels, saunas and bathhouses (Liu et al. 2004). Ren received a harsher sentence for the additional crime of drugging and robbing a person whom he had met during the course of these activities (ibid.).

Then, on 11 June 2004, in what was described as the first case of organized same-sex prostitution in China’s southeastern coastal city of Guangdong, the Yuexiu District People’s Court sentenced Liu Xianzhi and Zhou Deming to a fine of 1,000 yuan and five and six years imprisonment respectively for organizing prostitution (Li Meiyi 2004). Liu was sentenced for organizing commercial sexual services in the 24-hour 'Man's Dream' bar and commanding a commission of 30 yuan out of a minimum fee of 100 yuan from five young men whom he had retained for the purpose of providing handjobs and/or blowjobs to patrons of the venue. Zhou was sentenced for keeping 10 young men in rental residential premises for the purpose of providing male-male prostitution services, for restricting the personal movement of his 'employees' (in one instance keeping an individual locked in a separate room), and for commanding a weekly fee of 60 yuan for food and accommodation, and a commission of 30-50 yuan from a maximum fee of 300 yuan for facilitating the prostitution transaction (ibid.).

Finally, on 2 March 2005, in what was described as the first conviction for organized same-sex prostitution in China's southwestern province of Sichuan, the Jinniu District People’s Court in Chengdu City sentenced Tang Fajun to six years imprisonment and a fine of 5,000 yuan for organizing male-male prostitution services and violating an individual’s human rights (Li Yang 2005; Lü and Deng 2005; Yang Liu 2005; Yuan 2005). Unlike the preceding cases, which came to court following public reports of suspected offences to local police stations, this case came to 
light due a statement provided by a young male, rural migrant, Chen Minghui. In April 2004, Chen allegedly came to Chengdu from a remote township to find work and had been deceived by Tang, who had offered him employment as a waiter in a teahouse for a monthly wage of 600-800 yuan plus food and accommodation. However, Tang had then taken Chen to a residential home and forced him to have sex with 10 or more men over the course of a month (Lü and Deng 2005), other reports suggest that he was forced to service up to 20 and even 60 clients (Li Yang 2005; Yuan 2005). Chen claimed that he was initially beaten into compliance and then acquiesced to repeated acts of rape in an attempt to convince his 'employer' of his submission and thus enhance his opportunity to escape (ibid.). Conversely, Tang's defence was premised on the understanding that the other young men he had organized to sell sexual services not only did so on a voluntary basis, but also received high sums of money in recompense (Yang Liu 2005), thereby impugning the veracity of Chen's testimony.

The topical nature of these cases, combined with the fact that their incidence could be observed throughout the PRC, prompted Chinese media commentators to conclude that same-sex prostitution was an integral if overlooked component of China's burgeoning, albeit banned, sex industry (Fu 2004; Li Meiyi 2004). Indeed, many commentators argued that the Li Ning case simply exposed the 'tip of the iceberg' with regard to the extent of male-male commercial sexual services in China today (Fu 2004). Not surprisingly, media coverage of such cases often served as the springboard for a more extended discussion of issues pertaining to male-male prostitution and homosexuality in China more generally, and it is to an examination of these issues that I now turn. 


\section{Debating the social implications of male-male prostitution in the PRC}

As with most discussions of prostitution in Western societies, media coverage of China's 'first same-sex prostitution case' generated broader debate based on the standard anthropological-cumsociological questions: namely, who provides male-male prostitution services; what are their motivations for doing so; and, in what kinds of spaces do they provide such services? According to media commentators, a quick search of the internet, some candid talks with anonymous informants, and a series of interviews with some of China's growing number of 'sexperts', soon reveals that 'money boys' are a common feature of bar life in present-day China (Fu 2004). It bears noting here that the English phrase 'money boy' is often used in Chinese-language discussions rather than the Chinese equivalent of 'tongxingmaiyin' or same-sex sex seller, on the grounds that this is the terminology used by members of China's homosexual community themselves (ibid.). Concomitantly, members of China's homosexual community describe themselves interchangeably with reference to the English term 'gay', the Chinese term tongxinglian (same-sex love), and the Hong Kong-derived appropriation of the politically correct appellative for all Chinese citizens during the Maoist era, tongzhi or comrade (Rofel 1999: 465). Also in line with most discussions of prostitution in Western societies, Chinese media commentators tend to avoid related anthropological-cum-sociological questions such as: who demands male-male prostitution services; what kinds of venues do they frequent; and what are their motivations for doing so?, even though they posit as the presumed side of demand a generic community of people who are erotically inclined towards members of the same sex. 
Media commentaries suggest that the majority of 'money boys' in present-day China are young, unmarried men (approximately 18-24 years of age), from poor communities in the rural hinterland who have moved to urban and more developed parts of the PRC to look for work, and/or are university students with limited means of financial support (Fu 2004). On this issue, Zhang Beichuan, a noted medical scholar on the subject of men who have sex with men in China, estimates that there are between four and ten thousand male rural migrants who offer same-sex sexual services in the city of Beijing alone (Zhang Beichuan et al. 2000a). Most of these young men reputedly self-identify as heterosexual, but are willing to provide commercial homosocial sexual services in exchange for relatively high sums of financial recompense and flexible working hours (Fu 2004).

The prices commanded for the provision of male-male commercial sexual services vary depending on the nature of those services, the involvement of third parties, and the kinds of venues in which the prostitution transaction takes place. Quick transactions negotiated and conducted on the street command between 10-30 yuan, whereas sexual services that are arranged at or provided in recreational venues such as hotels, bars, karaoke/dance venues, saunas, health centres, fitness clubs, bathhouses, and teahouses, command between 50-300 yuan. 'Money boys' reputedly earn 300-400 yuan per month for providing hospitality and companionship services in such venues, with their income deriving from 'tips' and commission charged on the consumption of food and beverages (Fu 2004). They command a further 100-300 yuan for the prostitution transaction, in instances when they either utilize the facilities of a given venue, or else depart from that venue with a patron, in order to provide sexual services (ibid.). Media reports suggest that the owners or managers of such entertainment venues routinely extract a commission or 
‘management fee’ from ‘money boys’ for providing the space in which they can ply their trade, introducing them to prospective clients, and generally facilitating the prostitution transaction (ibid.). To date, the available literature does not address the question of who precisely demands the services of male sex sellers in present-day China, other than gesturing towards an unspecified group of usually married men (Zhang Beichuan et al. 2000a).

Given the rapid proliferation of venues for homosocial activities throughout the PRC, Chinese commentators often suggest that a gay subculture is emerging in the PRC; and, this development illustrates both the tolerant nature of traditional Chinese sexual culture and the progressive nature of China's continued opening up to the rest of the world. Academic and media commentators generally characterize the history of sexuality in China as follows. A traditional period of openness and toleration with regard to all forms of sexual practices was followed by a gradual but increasing series of governmental prohibitions on sex that culminated in the repression of the Maoist era, when the topic of sex allegedly became taboo and people were punished for a wide range of sexual 'transgressions'. Now, with economic reform and the abandonment of 'puritanical socialism', it is claimed that China is slowly reclaiming its former tradition of sexual tolerance and eclecticism, whilst simultaneously embracing the kinds of sexual behaviours that are associated with 'the more advanced and sexually liberated 'West' (Sigley and Jeffreys 1999: 50-8).

Extrapolating from this conventional account of the history of Chinese sexuality, concerned commentators tend to describe the history of homosexuality in China in terms of a shift from a culture of toleration and acceptance to one of repression and, more recently, back to a culture of 
acceptance. As they argue, homosexuality has a long and venerable history in (Confucian) Chinese culture, as evidenced by the documented love of certain emperors for their young male companions, and as depicted in eighteenth century novels such as the Dream of the Red Chamber (e.g. Geyer 2002: 262-64; Rubin 2003; see also Chou 2000; Hinsch 1992). That tradition was overturned during the Maoist period, when homosexuality was classified as a disease and homosexuals became subject to political attack (Li Yinhe 2006). This new culture of condemnation continued throughout the 1980s and early 1990s, during which 'gay males were routinely harassed, detained, interrogated, and often arrested and jailed each time a political or social movement of virtually any kind was announced’ (Geyer 2002: 263). But, recent social and legal changes indicate that homosexuality in the PRC is finally being accepted as a legitimate and natural expression of human sexuality once again (Li Yinhe 2006).

Subsequently, contrary to Western accounts of China as characterized by 'official homophobia' (Martin 2000: 81), some Chinese commentators describe the PRC as a 'half-heaven for homosexuals', based on the ambiguous status of homosexuality in contemporary Chinese society and law (Li Yinhe cited in McDonald 2005). Although homosexual identity is problematized in China as reflecting an aberrant choice of lifestyle, Chinese academics and media commentators similarly suggest that the act of engaging in same-sex sexual conduct per se carries little or no social stigma. Instead, they maintain that 'Chinese society’ views engagement in same-sex sexual behaviours as acceptable so long as such conduct occurs in private and does not interfere with the traditional social obligation for members of both sexes to marry and produce an heir (ibid.; see also Friess 2004; Geyer 2002; 'He tongxinglian youguan de falü’ 2003’). The standard argument here is that, unlike 'the West', homosexuals in China are not forced into 'the closet' by 
morally based religious proscriptions on same-sex sexual behaviours, and hence by social and self-internalized conceptions of guilt. Rather, they are constrained by the traditional Chinese expectation that everyone ultimately will enter into a monogamous heterosexual marital arrangement for the purposes of reproduction (Rubin 2003).

This perceived absence of moral taint arguably is reflected in the ambiguous status of homosexuality in Chinese law. As many commentators note, the increasingly tolerant legal attitude to homosexuality in China today is indicated by the fact that reference to 'hooliganism', an umbrella term that formerly was applied to men arrested while cruising for sex in public toilet blocks and parks, was removed from the 1997 criminal code; and, in March-April 2001, the Chinese Psychiatry Association removed homosexuality from its list of mental illnesses (Gao Feng 2003). These shifts are viewed as confirming a step taken by the Chinese Ministry of Public Security, which effectively declared homosexuality a private, not legal, concern in 1992, when it denied a father's request that the police arrest his daughter and her lesbian lover for cohabitation, arguing that the police had no cause to intervene, since China has no laws on homosexuality (ibid.; Gong 2003). Adding to these perceived signs of growing toleration and progressive 'civilizational' advancement, many commentators contend that the so-called former taboo on public discussions of sex and sexuality in China has been abandoned in favour of informed academic debate and the open provision of courses on gay and gender studies in Chinese universities. ${ }^{5}$ Hence, media commentators often draw on the work of recognized academics to imply that the provision of information about male-male prostitution is not about acquiring a voyeuristic readership or selling sex in a different form; rather, it is about guiding the 
public in terms of promoting increased tolerance through understanding of same-sex sexual behaviours (Fu 2004).

The subject of homosocial prostitution, however, occupies a problematic position in this generalized rendition of the PRC as a country that is joining an idealized conception of Euramerica in terms of viewing homosexuality as a legitimate and natural expression of human sexuality. On the one hand, media commentators draw on recent studies to indicate that the majority of self-identified homosexuals in China still enter into heterosexual marital arrangements in order to fulfill their filial obligations, i.e., to produce an heir (McDonald 2005; see also Gong 2003; Zhang Beichuan et al. 2000a; Zhang Beichuan et al. 2000b). And, given the general understanding in China that sex is a natural desire that requires an outlet (Yao Zixi (n.d.)), the existence of male-male prostitution is implicitly posited as an inevitable consequence of China’s continued adherence to a traditional family system. Viewed in this context, the existence of male-male prostitution is presented as inevitable but still undesirable, with the most pressing problem being construed as the form in which male-male commercial sexual services occur. Put simply, the provision of public and promiscuous commercial sex in bathhouses, saunas, health centres, and so forth, is looked upon with moral disapproval, whereas the recent shift to more discreet forms of male-male commercial sexual services, in the form of using the internet and mobile phone technology to advertise services and arrange meetings with clients, is viewed as less public and therefore potentially more acceptable (Fu 2004; see also Freund 2001; Langfitt 2000). 
On the other hand, it appears that members of China's homosexual community and concerned academics both view sellers of male-male commercial sexual services as problematic in various ways. In 'Qualities of desire: imagining gay identities in China’, Lisa Rofel (1999: 451-74) draws on interviews with self-identified gay men in Beijing to argue that members of China's emerging gay community view the existence of 'money boys' with considerable anxiety. As Rofel (1999: 466) notes, Beijing gays look down on 'money boys', describing them as uneducated and 'poor quality' rural youth, who contaminate the advancement of urban 'homosexual culture', and destroy the perceived purity of homosexual love, by bringing 'money or materiality' into the equation. This way of categorizing 'money boys', she concludes, not only divides gay men, but also establishes hierarchical distinctions between 'proper and improper expressions of gay identity’ (ibid.). Following talks with self-identified members of China’s gay community in Nanjing and Shenzhen, Fu Jianfeng (2004) similarly notes that many gay men view 'money boys’ as criminal ‘low-lifes’ who bring the homosexual community into disrepute, and whose activities need to be curbed via the implementation of stricter governmental controls. This apparent rejection of male-male prostitution as an acceptable component of homosexual life in China raises the question of who precisely demands the services of 'money-boys', whilst simultaneously pointing to the existence of an emerging consensus regarding the question of what is considered to be the appropriate range of same-sex sexual behaviours.

Most notably, Chinese academics, policing scholars, and self-identified members of China's homosexual community, similarly contend that male-male prostitution needs to be made subject to governmental constraints in order to curb the PRC's rapidly increasing rate of HIV/AIDS infection (Guo Xiaofei 2004). As in many other countries, adherence to World Health 
Organization (WHO) directives has ensured that homosexual and prostitutional sex have been problematized as 'high-risk' sexual practices and potential vectors for the spread of HIV/AIDS in China. Hence, on 1 December 2004, the Chinese Department of Health and Hygiene issued the first official estimate of the male homosexual population in the PRC to the world-an estimated 5-10 million people (Lü 2004). This figure is highly conservative when compared to those provided by journalists and scholarly commentators. Extrapolating from Alfred C. Kinsey’s contention that 3-4 percent of a given population is homosexual, ${ }^{6}$ they suggest that there are between 36-48 million adult gays and lesbians in China today (Gong 2003; Rubin 2003; Zhang Beichuan et al. 2000a). Numerical discrepancies aside, recent discussions of homosexuality in China share a common concern. As many commentators argue, male homosexuals comprise a substantial yet overlooked proportion of the Chinese population; moreover, surveys indicate that homosexual men constitute the second major risk group for the spread of HIV/AIDS in the PRC after intravenous drug users, with an estimated 70-80 percent of that group being married, and 50 percent engaging in sexual intercourse with their female partners. In consequence, understanding the sexual behaviours of China's male homosexual population and making that population aware of safer sex practices and the goals of HIV/AIDS prevention is construed as vital for safeguarding China’s future (Zhang Beichuan et al. 2000a).

While drawing on concerns over high-risk sexual behaviours to advocate stricter legal controls over homosocial prostitution, Chinese law enforcement authorities insist that they are not opposed to homosexuality; they are simply against the organization of commercial sexual services (Xiao and Qing 2004; Yao Zixi (n.d.)). Unlike Western media commentators, who often use cases such as Li Ning's to suggest that 'gayness' is treated as equivalent to vice in the PRC 
('China cracks down on gay prostitution' 2004; 'Police arrest 37 gays in social vice swipe' 2000), Chinese media commentators maintain that Li Ning's conviction does not signify that China is anti-gay. Rather, it highlights the PRC's continued commitment to the abolition of prostitution, and, insofar as it sends a warning to the homosexual community, that warning is not to engage in what are considered to be new and inappropriate same-sex sexual practices, i.e., homosocial prostitution (Xiao and Qing 2004; Yao Zixi (n.d.)).

The suggestion that homosexuality is acceptable but commercial sex is not is reiterated in discussions concerning the implications of China's entry to the World Trade Organization for homosexuality and the law. Media commentators often cite Gong Guojiang, who completed an MA at Beijing University Law School on precisely this subject, to argue that Chinese law needs to be expanded in order to protect the rights of homosexuals as Chinese citizens ('Tongxinglianzhi de gongminquanli he fazhijianshe' 2003). The general contention here is that the rights of homosexuals as citizens will be guaranteed by legalizing same-sex marriage, by legislating against the existence of 'money boys', and by specifying in law that the rape of men by men and the forced prostitution of men are criminal offences (ibid.). These arguments received a recent airing in the Chinese media following a statement made in June 2005 by Liu Baiju, a member of the Chinese People's Political Consultative Conference, on the subject of non-consensual same-sex sexual violence. According to Liu, sex-related legislation in China to date has concentrated on the task of protecting women's rights and interests and has failed to extend the same protections to members of the male population. He therefore recommends that China move towards protecting and promoting men’s sexual rights by acknowledging in criminal law that men too can be victims of sexual violence (Xie Wei et al. 2005). This recommendation 
is likely to be taken up at the forthcoming meeting of China's top legislative body, the Standing Committee of the National People’s Congress, in 2006.

Conversely, other media commentators point out that noted Chinese academics such as Li Yinhe and Pan Suiming have variously argued that China must relax its opposition to the prostitution industry, both in order to protect the human rights of sellers of commercial sex and to comply with WHO directives regarding the promotion of HIV/AIDS education and safer sex practices (Fu 2004). The question of exactly how China should revise its prostitution laws remains a matter of dispute: some commentators favour decriminalizing the prostitution transaction, i.e., removing the prostitution transaction from the purview of the Chinese system of administrative sanctions (e.g. Li Yinhe 2005; Pan Suiming 1998), whereas others argue for stricter controls over the organization of prostitution and an increased focus on the historically neglected side of demand (e.g. Zhu 2003). However, outreach work that targets providers of commercial sexual services is becoming more common in China, and, in accordance with the funding obligations of organizations such as the Ford Foundation, that work not only emphasizes the provision of free condoms and safer sex education in public entertainment venues, but also constructs providers of commercial sexual services as disadvantaged workers who require labour and health protections (Lü Fuming 2004).

At the same time, growing HIV/AIDS awareness among Chinese officials and the general public has generated contradictory outcomes for providers of both heterosexual and homosocial commercial sexual services. Governmental recognition of the economic and social implications of the spread of HIV has resulted in the implementation of much-needed HIV/AIDS education 
programmes. But this same recognition has prompted the implementation of stricter regulations over workers in certain sectors of China's hospitality and service industry. For example, in February 2005, the Departments of Health and Hygiene, Industry and Commerce, and Culture, in Henan Province, jointly issued new regulations that require all workers in the hospitality and service industry to undertake testing and training vis-à-vis sexually transmissible infections (STIs), including HIV/AIDS, as a condition of legitimate employment (Han Junjie 2005). The same regulations stipulate that owners of recreational enterprises must ensure that all their employees undergo the requisite testing and training, and that employees are registered under their proper (i.e., legally verifiable) names with the Department of Disease Control, as a condition of conducting business (ibid.). ${ }^{7}$ The stated rationale for introducing these regulations is to prevent the spread of STIs and HIV/AIDS from those categorized as 'high-risk' members of the population to those categorized as ‘ordinary’ members of the population. Insofar as recreational venues that are known sites for the provision of commercial sexual services are cited as potential sites of disease transmission, i.e., karaoke-dance venues, hairdressing salons, saunas, bathhouses, and venues offering foot-washing and other forms of massage, these regulations clearly target providers of commercial sexual services, even though the regulations do not explicitly state this. In China, as in the West, therefore, the imperatives of HIV/AIDS prevention work has encouraged a paradoxical pathologization of participants in prostitutional and same-sex sexual behaviours as vectors of disease; whilst simultaneously constructing participants in commercial sexual practices as sexual minorities who possess identifiable needs and rights that require improved social awareness and new legal protections. 


\section{Conclusion}

To summarize the preceding remarks, there are numerous impediments to self-identifying and living openly as a 'gay' in present-day China; and, there are clear restrictions on the public display and consumption of what some might term an open and transgressive 'gay lifestyle'. Western commentators often cite these impediments as reflective of the traditional and repressive ethos of the Chinese Party-state vis-à-vis the governance of sex-related issues in general. However, an examination of the public debate surrounding Li Ning's conviction for organizing male-male prostitution indicates that the relationship between sex and government in contemporary China cannot be characterized as marked by straightforward repression, official homophobia, and a corollary refusal to embrace the rights, and accompanying legal strategies, that are associated with progressive, liberal sexual politics.

Although more localized struggles for improvements in the status of China's homosexual community are required, an examination of the debate surrounding Li Ning's conviction suggests that discussions of homosexuality in the PRC turn on what Lisa Rofel (1999: 464) describes as 'an economy of sex and sociality that is distinct from an economy of the closet'. In Rofel's words, 'the visions of many Chinese gay men in China about what it means to be gay are certainly connected to the knowledge that gay people exist all over the world', but 'these men do not simply imagine a global community of horizontal comradeship’ (ibid.: 470). Imaginings of gay identity in the PRC are both constrained and enabled by the fact that being homosexual is not understood in terms of an inherent yet repressed identity, or 'the existence within the self of a separate sexual domain that is a constitutive principle of the self' (ibid.: 464). Instead, 
homosexual identification is negotiated within conceptions of 'face' and 'status' that continue to invoke both the family and the nation as forces that are constitutive of one's social being. To the extent that this characterization is apposite, the queer rendition of promiscuous and commercial homosocial sex as rightful expressions of a transgressive consumer lifestyle is unlikely to receive much support in China.

\section{References}

Altman, D. (2000) 'Talking sex’, Postcolonial Studies, 3, 2: 171-78.

'Chengdushi xingbing aizibing fangzhi guanli tiaoli’ [Chengdu City STIs and HIV/AIDS prevention and management regulations] (2000) 27 October, http://www.tsinghua.edu.cn/docsn/shxx/site/chinac/liudb/aids/lanmu/qinghua/tzh/baogao/38.htm (accessed 21 July 2005).

‘China cracks down on gay prostitution’ (2004) UPI NewsTrack, 15 June.

‘China: law faces sex problems—Sichuan teahouse case’ (1999) Sinofile Information Services, 15 May.

Chou, Wah-shan (2000) Tongzhi: Politics of Same Sex Eroticism in Chinese Societies, Binghampton, N.Y.: Haworth Press. 
'Couple arrested in China for running gay prostitution bar' (2003) www.gmax.co.za, 22

September.

Criminal Law of the PRC (1997) adopted by the Second Session of the Fifth National People's Congress on 1 July 1979 and amended by the Fifth Session of the Eighth National People’s Congress on 14 March 1979, http://www/chinajnbook.com/business/criminal01.htm (accessed 21 July 2005).

Engels, F. ([1884] 1972) The Origin of the Family, Private Property and the State, New York: International Publishers.

Fan Huawei and Guo Zhenyu (2004) ‘Nanjing tongxingmaiyin’an diaocha’ [An investigation of Nanjing’s same-sex prostitution case], www.cyol.net, 5 March.

Freund, C.P. (2001) ‘Gay Cathay: laws concerning homosexuals in China’, Reason, June.

Friess, S. (2004) 'Gay men, lesbians in China attend Tongzhi Conference’, Chicago Tribune, 9 May.

Fu Jianfeng (2004) 'Fayuan panjue: tongxingmaiyinzui chengli’ [Court decision: the crime of same-sex prostitution exists], Nanfang dushi bao, 18 February. 
Gao Feng (2003) 'Zhongguo tongxinglian quanjilu’ [A complete record of homosexuality in China], Jinyangwang, http://heritage.tom.com/Archive/2001/7/30-86494.html (accessed 18 December 2003).

Geyer, R. (2002) 'In love and gay’, in P. Link, R.P. Madsen and P.G. Picowicz, Popular China: Unofficial Culture in a Globalizing Society, Lanham; Boulder; New York; Oxford: Rowman and Littlefield, 251-74.

Grewal, I. And Kaplan, C. (2001) 'Global identities: theorizing transnational studies of sexuality, GLQ, 7, 4: 663-79.

Gong Guojiang (2003) ‘Jiaqiang woguo de tongxinglian fazhi jianshe’ [Strengthen China’s legal system with regard to same-sex love], www.chinag.org, 8 October, http://www.chinag.org/shownews.asp?news_id+335 (accessed 18 December 2003).

‘Gong’anbu guanyu dui tongxing zhijian yi qiancai wei meijie de xingxingwei dingxing chuli wenti de pifu' [A reply from the Ministry of Public Security on how to define and handle the exchange of same-sex sexual conduct for money or property] (2001) 23 August, Order 4.

Guo Xiaofei (2004) ‘Tongxingmaiyin’an tuxian falü kongbai’ [Same-sex prostitution case reveals gaps in the law], www.civillaw.com.cn, 8 April. 
Guo Xiaosong (2004) ‘Jiangsu shouli tongxingmaiyin’an zhong kaiting’ [The court hearing of the first case of same-sex prostitution in Jiangsu finally begins], Dongfang weibao, 13 February.

Han Junjie (2005) ‘Henan yule changsuo shishi shimingzhi shanggang qian xu jieshou aizibing jiance' [Henan Province implements a proper name system in entertainment venues: workers must have a HIV/AIDS test before commencing employment], Zhongguo qingnian bao, 20 February.

‘He tongxinglian youguan de falü’ [Laws pertaining to homosexuality] (2003) Qianlong.com, 20 November, http://www.qianlong.com/2955/2003/11/20/41@1723211.htm (accessed 18 December 2003).

Hinsch, B. (1992) Passions of the Cut Sleeve: The Male Homosexual Tradition in China, California; University of California Press.

Honig, E. (2003) 'Socialist sex: the Cultural Revolution revisited’, Modern China, 29, 2: 143-75.

Jeffreys, E. (2004) China, Sex and Prostitution, London; New York: RoutledgeCurzon.

Langfitt, F. (2000) 'Out of closet, onto internet’, Baltimore Sun, February. 
Li Meiyi (ed) (2004) ““Yatou” caokong nanji maiyin: Guangdongsheng zuzhi tongxingmaiyin'an' [Guangdong gives a verdict on the first case of organized male same-sex prostitution in the province], Southcn.com, 12 June.

Li Yang (2005) ‘Xi’nan diqu shouli qiangbi nanzimaiyin’an “laobao” zhou shoushen’ [Yesterday the southwestern region heard the first case concerning an organizer who forced men into prostitution], Chongqing shangbao, 25 March.

Li Yinhe (1998) Tongxinglian yawenhua [The Subculture of Homosexuality], Beijing: Jinri Zhongguo chubanshe.

Li Yinhe (2006) ‘Regulating male-male love in the People’s Republic of China’, in Elaine Jeffreys (ed.) Sex in Post-Mao China, London; New York: RoutledgeCurzon.

Li Yinhe (2005) 'Woguo yinggai ba maiyin dang daode wenti chuli’ [China should handle prostitution as a moral [not legal] issue], Jinyangwang, http://www.yfs.gov.au, 14 May.

Liu Nianxian, Zhang Yumei and Guo Ying (2004) ‘Jilin shouli tongxingmaiyin’an xuanpan’ [A verdict is reached on Jilin’s first case of same-sex prostitution], Jilin ribao, 26 May.

Liu Yaotang (2004) ‘Jiaofeng: “tongxingmaiyin” duo wenlun’ [Confrontation: different perspectives on 'same-sex prostitution'], http://www.148china.com/ReadNews.asa?NewsID=1112 (accessed 1 June 2005). 
Liu Yaping (2004) ‘Cong Nanjing shouli tongxingmaiyin’an kan “zuixing fading”’ [The first case of same-sex prostitution in Nanjing reveals the legal definition of a crime], 18 March, http://www.148china.com/ReadNews.asa?NewsID=1112 (accessed 1 June 2005).

Liu Zhi (n.d.) ‘Nanjing tongxinglian maiyin’an’ [Nanjing’s homosexual prostitution case], Fenghuang zhoukan, vol. 141.

Lü Fuming (2004) 'Zhongguo shouci gongbu nantongxinglian renshu’ [First public statistics on male homosexuality in China], Xinhuanet.com, 1 December, http://news.xinhuanet.com/health/2004-12/01/content-2280536.htm (accessed 6 June 2005).

Lü Jian and Deng Jian (2005) ‘Jin shen quansheng shouli qiangpo tongxingmaiyin’an’ [The first case of forced male-male prostitution in [Sichuan Province] is heard today], Chengdu shangbao, 24 February.

Martin, F. (2000) 'From citizenship to queer counterpublic: reading Taipei’s new park', Communal/Plural, 8, 1: 81-94.

McCamish, M., Storer, G., and Carl, G. (2000) 'Refocusing HIV/AIDS interventions in Thailand: the case for male sex workers and other homosexually active men', Culture, Health and Sexuality, 2, 2: 167-82. 
McDonald, H. (2005) 'Gay revolution puts red China in the pink’, Sydney Morning Herald, 27 August.

Pan Suiming (1998) 'Zhongguo de jinchang zhengce yu shiji qingkuang fenxi' [An analysis of China’s policy of banning prostitution and its effects], Bamian laifeng, November.

'Police arrest 37 gays in social vice swipe’ (2000) China News Digest, 10 July.

Pomfret, J. (2001) 'Chinese city is first to enact law on AIDS: controversial rules set for infected people, high-risk groups’, Washington Post Foreign Service, 15 January, A16.

Quanguo renda changweihui, xingfashi bianzhu, fazhi gongzuo weiyuanhui [Criminal Law Office and the Legal Council of the Standing Committee of the National People’s Congress] (1991) Guanyu yanjin maiyin piaochang de jueding he guanyu yancheng guaimai banjiafunü, ertong de fanzui fenzi de jueding shiyi [An Explanation of the Decision on Strictly Forbidding the Selling and Buying of Sex and the Decision on the Severe Punishment of Criminals Who Abduct and Traffic in or Kidnap Women and Children, Beijing: Zhongguo jiancha chubanshe.

Rofel, L. (1999) 'Qualities of desire: imagining gay identities in China’, GLQ, 5, 4: 451-74.

Rubin, K. (2003) 'How to be gay in Beijing', The Gay and Lesbian Review Worldwide, 10, 3: 29-33. 
Shi Meitang (n.d.) ‘“Maiyinpiaochang” kefou geiyu hefa diwei?’ [Should prostitution be legalized or not?], Law-China, http://www.law-china.com/15/cp150004.htm (accessed 3 September 2003).

Sigley, G. and Jeffreys, E. (1999) 'On “sex” and "sexuality” in China: A conversation with Pan Suiming', Bulletin of Concerned Asian Scholars, 31, 1: 50-8.

Starr, J.B. (2001) Understanding China: A Guide to China's Economy, History and Political Structure, London: Profile Books.

‘Tongxinglian zhide gongmin quanli he fazhi jianshe’ [Homosexual rights and rule of law] (2003) Sina.com, 5 December, http://www.sina.com.tw/man/n/2003-12-05/4851.html (accessed 18 December 2003).

Wan Yanhai (1997) 'Sexual work and its public policies in China', International Conference on Prostitution: An Interface of Cultural, Legal and Social Issues, The Centre for Sex Research, California State University, Northridge and COYOTE LA, 13-16 May.

Wei Yi (2004) 'Zhanzai zuixingfading de lichang wei Nanjing tongxinmaiyin’an bianhu’ [Using the perspective of criminal law to defend the Nanjing same-sex prostitution case], Shanghai faxuewang, 20 June, http://www.yfzs.gov.cn (accessed 6 June 2005). 
Xiao Jie and Qin Xing (2004) ‘Jiangsu shouli tongxingmaiyin’an yi shen panjue’ [A verdict is reached on Jiangsu's first same-sex prostitution case], http://www.lawbase.com.cn/consult\%5Cclassic_lawcase_view.asp?op=4\&classic_lawcase_id=1 96 (accessed 25 March 2004).

Xie Wei, Shen Jianli and Lia Wenhua (2005) ‘Liu Baiju weiyuan: tongxing xingqinfan yingding “weishezui”' [Liu Baiju (a member of the Chinese People’s Political Consultative Conference) says: same-sex sexual violence should be defined as 'molestation crime'], Guangming ribao, 6 June.

Yang Liu (2005) 'Sichuan shenpan shouli qiangpo nanzi maiyin’an beigao beipan liunian tuxing’ [Sichuan comes to a verdict on the first case of forced male prostitution: the defendant is sentenced to six years imprisonment], Chengdu wanbao, 3 March.

Yang Tao (n.d.) ‘Cong “Zhengqiba” zuzhi tongxingmaiyin’an kan “ge’an qingshi”’ [The 'Zhengqi Bar' same-sex prostitution case raises questions about the practice of 'asking for instructions on specific cases'], http://www.148china.com/ReadNews.asa?NewsID=1112 (accessed 1 June 2005).

Yao Lan (2004) ‘Gay pimp gets one year in prison’, China Daily (North American ed.), 13 January, p. 3. 
Yao Zixu (n.d.) ‘Tongxingmaiyin de zui yu fa' [Same-sex prostitution: crime and punishment], http://www.fmedsci.com/printpage.asp?ArticleID=1852 (accessed 21 March 2005).

Yuan Xin (2005) ‘Tongzhi chalouli de exing’ [Evil conduct in a homosexual teahouse], Minzhu yu fazhi bao, 9 May.

Zhang Beichuan, Li Xiufang, Hu Tiezhong, Liu Dianchang, and Shi Tongxin (2000a) ‘Dui nannanxingjiechuzhe de aizibing ganyu: lilun yu shijian’ [Theory and practice: AIDS intervention concerning men who have sex with men], Zhongguo xingbing aizibing fangzhi, vol. 3.

Zhang Beichuan, Liu Dianchang, Li Xiufang, Hu Tiezhong (2000b) ‘A survey of men who have sex with men: mainland China’, American Journal of Public Health, 90, 12: 2 pgs.

Zhang Chenyi (2003) ‘Shanghai fayuan panchu yizuzhi tongxingmaiyin’an beigaoren panxing sannian' [Shanghai court rules on a case of organized same-sex prostitution: the organizer is sentenced to three years], Chinanews.com, 9 July, http://www.chinanews.com.cn/n/2003-0709/26/322309.html (accessed 25 March 2004).

Zhang Ning (2005) ‘2004 Zhongguo shida anjian’ [China’s 10 biggest legal cases in 2004], Xinhua News Agency, 10 January, http://www/dps.In-gov.cn/zazj/Print.asp?ArticleID=3666 (accessed 29 April 2005). 


\title{
Zhonghua renmin gongheguo guowuyuan [State Council of the PRC] (1999) Yule changsuo
}

guanli tiaoli [Regulations concerning the management of public places of entertainment], Beijing: Wenhua chubanshe.

\section{Zhu Jiaolong (2003) ‘Saohuang yinggai zhua jinü haishi piaoke?’ [Should campaigns against}

prostitution and illegality target the sellers or buyers of sex?], Nanfang dushi bao, 2 December.

\author{
Zong Yiduo and Yang Fan (2004) 'Zhongshen weichi banian xingqi: Nanjing “yaba” maiyin’an' \\ [Final verdict: eight years for Nanjing’s ‘homosexual prostitution’ case], www.163.com, 11
}

May, http://news.163.com/2004w05/12549/2004w05_1084257103045.html (accessed 8 July

2004).

\footnotetext{
${ }^{1}$ The nine other cases were: 1) the case of counterfeit baby formula in Anhui Province; 2) the case of corruption brought against the Vice-president of the Anhui Provincial Government; 3) the case of Ma Jiajue, a student at Yunnan University who murdered four of his room-mates; 4) the case of a counterfeit winning ticket in a BMW lottery held in Xi'an; 5) the case of a Nanjing law firm that sued the Bureau of Industry and Commerce for failing to protect trademark legislation; 6) the case of Internet pornography in Chengdu City; 7) the Guangzhou smuggling case; 8) the case of police corruption in Jilin, which entailed giving 10,000 driving licenses to people who had not been required to first take a driving test; and 9) the case of the International Music Products Association suing more than 10,000 karaoke dance-venues for violating copyright and using MTV without paying requisite royalties. ${ }^{2}$ This does not mean that the Li Ning case constitutes the first known case of homosocial prostitution in China. On 15 December 2001, two unspecified men in Beijing were sentenced to nine and six year's imprisonment respectively for running a male-male prostitution business (Gong 2003). In July 2003, the Shanghai Changning District Court sentenced Wang Zhiming to three years imprisonment and a fine of 3,000 yuan for organizing four young men to sell sex from a rented residential premise (Fu 2004; Liu Yaotang 2004). The court allegedly handed down a lenient sentence in this case because Wang Zhiming gave himself up to the police and admitted his guilt (Zhang Chenyi 2003). And, on 12 January 2004, the Huangpu District People’s Court in Shanghai sentenced Shao Wei to imprisonment for one year and a fine of 1,000 yuan for harbouring male prostitutes in a bar (Yao Lan 2004: 3). ${ }^{3}$ For a discussion of the implications of this distinction with regard to the provision of male-male commercial sexual services in Thailand, see Malcolm McCamish et al. (2000: 167-82).

${ }^{4}$ This 'Reply' was made in response to requests from lower-level public security authorities in Guangxi Zhuang Autonomous Region for advice on how to deal with the phenomenon of same-sex prostitution.

${ }^{5}$ Although claims that 'sex' disappeared during the Maoist period have been called into question (Honig 2003: 14375), it remains the case that public and academic discussions of issues of sex and sexuality have increased dramatically in the reform period, and that the provision of sex-related courses at Chinese universities is a recent phenomenon. Scholars and activists who are credited with opening public debates on homosexuality and gay rights in present-day China include: Gong Guojiang (2003), Li Yinhe (1998), Wan Yanhai (1997), and Zhang Beichuan (2000a, 2000b).
} 
${ }^{6}$ The sexologist, Alfred C. Kinsey, is famous for conducting the largest quantitative studies of human sexual behaviours in the USA during the 1940s and 1950s.

${ }^{7}$ These regulations constitute a formal advance on a controversial set of regulations that were introduced in Chengdu City, Sichuan Province, in 2000. See 'Chengdushi xingbing aizibing fangzhi guanli tiaoli’ 2000; Pomfret 2001; Rubin 2003. 